\title{
Analysis on Influencing Factors of Price Concession in Expressway PPP Mode
}

\author{
Zhongfu Qin ${ }^{1, a,{ }^{*}}$ and Xiaodong $\mathrm{Wu}^{2, \mathrm{~b}}$ \\ ${ }^{1}$ Zhejiang University, 866 Yuhangtang Road, Hangzhou, Zhejiang Province, China \\ ${ }^{2}$ Room AnzhongA525, Zijinggang Campus of Zhejiang University, Hangzhou, Zhejiang Province, \\ China \\ ", a qinzhongfu@zju.edu.cn, b21612215@zju.edu.cn
}

Keywords: Concession price, direct influence factor, indirect influence factor.

\begin{abstract}
In order to make clear influencing factors of the expressway concession price based on PPP model, according to different concession price impact mechanism, three direct influencing factors are figured out by the use of literature review and systematic analysis, including government, the private sector and public person, as well as three indirect influencing factors, such as economic environment, political legal environment and industry environment. In addition, relations between them are analyzed.
\end{abstract}

\section{Introduction}

The toll management of the highway is the main means of recovering capital and profitability by using the PPP model for the investors. At present, the toll road in our country accounts for more than $90 \%$ of the highway. However, due to the late start and the lack of guidance by systematic theory and the perfection of the policy, highway tolls in our country also generally have high charges, inconsistent charging standards, unrealistic charging rates and regulation methods, and the impact of enterprise operation Highway public welfare and other issues, to the regional economic and social development, the people's production and life a series of negative effects.

Therefore, along with the popularization of PPP model in expressways, it is urgent and necessary to find out the influencing factors of expressway franchise prices and provide a theoretical basis for the formulation of reasonable franchise prices.

\section{Literature Reviews}

There are many factors that influence the toll standard of expressway. Many scholars at home and abroad have done much research in this field. Many scholars consider all factors that may affect the charging standard in the process of studying highway toll standard.

A.Chen believed that cost of financing, capital structure, project operation, project operation mode, traffic conditions, regional economic development level and resident income should be taken as key research objects [1]. Y.Duan analyzed influencing factors of highway pricing, including cost elements, investment income, toll period, vehicle flow, and risk and consumer income. And vehicle flow was found to be the most important factors that influence pricing through empirical study [2]. In this case, some scholars also classified the influencing factors according to the influence mechanism from different angles. According to the difference between effect mechanism and impact on expressway toll rate, W.X. Xu divided the influencing factors into two categories, namely direct influence factors and indirect influence factors. The former mainly included traffic volume, cost, management objective and macro-policy, which set the basis for the formation of fee scale. The latter included regional economic development level, road conditions, the willingness of consumers to pay, which played an indirect role in the process of charging standard formation [3]. C.W.Sun divided influencing factors that determined the toll standard of freeway into three categories from the point of 
view of pricing model, including total factors of cost and rate of return, traffic volume and allocation of fees, correction of bearing capacity and price index [4].

\section{Analysis of Main Influencing Factors and Mechanism}

To sum up, six main influencing factors are sorted out. From the viewpoint of nature, government, the private sector and public people are found to be main project stakeholders, while economic environment, political and legal environment, industry environment are the overall environment faced by the project. From the prospective of formulation of price concession, stakeholders or participants with different specific goals play a direct role in determining the price, while environmental factors indirectly affect price through influencing stakeholders. Therefore, all kinds of factors are analyzed in steps from stakeholders' perspective and environmental perspective.

Table 1. Influencing factors and their concepts

\begin{tabular}{|c|c|}
\hline Factor & Concept \\
\hline Government & Sponsor of the protect, whoes goal is to maximize the social benefits. \\
\hline The private sector & Pinanciers, builders and operators of the protect, whoes goal is to maximize profits. \\
\hline Public & $\begin{array}{c}\text { Potential consumers of the project, whoes goal is to use the products / services as cheap as } \\
\text { possible. }\end{array}$ \\
\hline $\begin{array}{l}\text { Economic } \\
\text { environment }\end{array}$ & $\begin{array}{c}\text { The macroeconomic situation where the protect is located,such as the social development, } \\
\text { national economic policy. }\end{array}$ \\
\hline $\begin{array}{l}\text { Political and legal } \\
\text { environment }\end{array}$ & The political system, policies and regulations, laws and regulations that the project faces \\
\hline Industry environment & The scale, competition and layout of the industry. \\
\hline
\end{tabular}

\section{Impact of Stakeholders on Concessionary Price}

Government, the private sector and the public exert different influence in determining the concession price. According to Road Act, the toll standard for vehicles is proposed by the collection unit, then submitted to the transportation department of the people ' s government of province, autonomous region and municipality for examination and approval with competent department of price administration. That's to say, expressway tolls are finally decided after weighing benefits of multiple party. Then the government is responsible for examination and approval. In other words, the private sector formulates the standard, but the government is truly final decision maker. As potential users, the public is indirectly involved in the process of setting price through serving as an important consideration of the private sector and taking part in government's the approval hearings. Similarly, P.C.Yao defined PPP pricing of highway as a double-layer goal programming. As top decision-makers, government and private sector decided charge and traffic capacity, while road users as lower-level decision makers developed their own strategies in compliance with the former strategy. Then top decision-makers adjusted the strategy according to the user's travel information [5]. In that case, it can be concluded that government and private sector are directly involved in the formulation process and play a direct role, while the public plays an indirect role (through the government and the private sector).

The public's influence on the government. As the leader of PPP project, the government must provide public goods that meet the social needs in order to maximize social benefits. The public hopes to spend as little as possible to use the freeway on the premise of ensuring quality. From the angle of social benefit, the government needs to satisfy demands of the public. Otherwise violate its original intention to initiate the PPP project. When studying the pricing mechanism of PPP under different demand states, B.Song put forward that different demand states of the market would lead to differences between price regulations formulated by public sectors, especially reflected by the allocation of pricing power [6]. Therefore, it's believed the government needs to take into account the public's income and economic affordability when pricing, as well as to their needs for the highway.

The public's impact on the private sector. When setting price, on the one hand, the private sector hopes to raise the price as soon as possible to make profits, on the other hand they should also 
consider users' differential benefits, which refers to benefits of users to choose highway in contrast with other travel ways. Once the price exceeds certain limitation, users will give up the highway and choose the other way, leading to reduction in usage, which may make it difficult to reach a certain rate of return on investment, taking Beijing Wuhuan Toll Toad as a typical example. In addition, X.Yi divided passenger flow production, passenger flow development and relative steady of passenger flow the moment conducting research on pricing strategy of PPP rail. Then according to different characteristics of three stages, the pricing strategy was analyzed [7]. Thus, the private sector should consider public acceptance of price when pricing, which is a very important factor.

The government's impact on the private sector. Government mainly has supervision impact on private sector in the pricing process. Due to public product property, monopoly and public welfare of highway, the private sector may carry out monopoly pricing for the maximization of their own interests if the concession price can't be regulated, damaging public interest and reducing the production efficiency. At the same time, from the point of view of PPP project partners, the private sector as main body in project financing, construction and operation can't reduce their participation in the PPP project for benefits under the regulation of government. It's necessary to carry out price subsidies.

\section{The Impact of Environmental Factors on Stakeholders}

The impact of the economic environment. The economic environment mainly affects PPP project through the cost, income and other factors. For example, the increase in lending rate leads to a rise in construction investment, so the private sector is required to make up for it. Meantime, the area of higher per capita disposable income can afford higher price. S.X.Duan proposed the public tolerance of the fare mainly depended on local economic development. The more advanced it was in economic development, the more conducive it was to increase traffic flow [8]. Therefore, it's believed that economic environment indirectly affects the formulation of concession price mainly through influencing the private sector and public.

The impact of political and legal environment. Political risk is less likely to happen, but once occurs, serious consequences are inestimable. Stable political environment guarantees each parties involved, such as perfect legal environment. W.G.Yu contended that a complete system of laws and regulations helped to protect interests of social capital, restrained government power and reconciled interests of all parties [9]. Good political and legal environment also proposes regulatory requirements for the government while enhancing private sectors' sense of security, which is a positive signal for setting concession price. For one thing, risk reduction decreases the uncertainty of project, so that the price is more reasonable. For the other hand, legal constraints for both sides makes the price more effective in balancing interests of all parties. Political and legal environment indirectly affects the formulation of the price by influencing the private sector and government.

The impact of the industry environment. Alternative public infrastructures of highway, such as competitive routes and provincial roads, also affect the price. Travel ways can be varied, which reduces the public's acceptable maximum price for the PPP project to some extent. Additionally, the private sector will be more cautious in pricing to avoid the loss of potential consumers. In addition, technological development, average profit margin and others will be important factors for the private sector. J.Y.Wang argued that the competitive market of expressways was a competition among highly centralized market with monopoly attributes, which promoted enterprises to set sustainable prices, and protected interests of partners at the same time of making a reasonable profit, so as to maximize the social welfare [10]. Therefore, it is believed that the industry environment indirectly affects concession price through influencing the private sector and the public. 


\section{Model Building}

Based on the above analysis of the impact of various factors on the mechanism, this paper proposed a model of influencing factors of Price Concession in Expressway PPP Mode, shown in Figure 1.

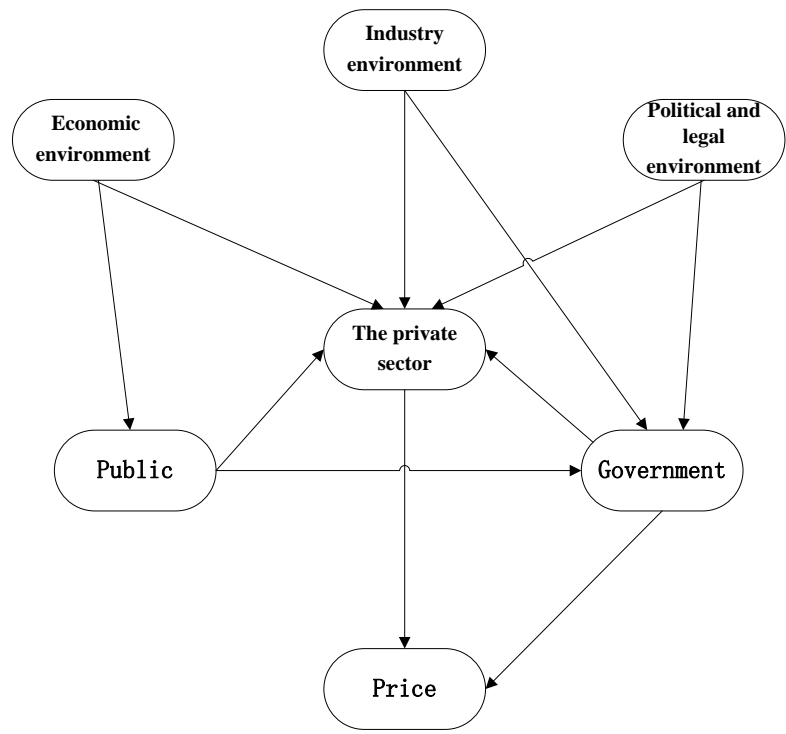

Figure 1. Model of influencing factors

\section{Summary}

According to different concession price impact mechanism, we figure out three direct influencing factors, including government, the private sector and public person, as well as three indirect influencing factors, such as economic environment, political legal environment and industry environment. The study found that the private sector and the government are the most direct contributors to the concession price. The public influences the concession price by influencing the private sector and the government indirectly, economic, political and legal environment, and industry environment affect the concession price by affecting three stakeholders.

\section{References}

[1]. A.Chen and K.Subprasom: Transportation Research Part A. Letters 41, 537-540 (2006).

[2]. Y.Duan, "The research on expressway's concession operation and pricing," Ph.D. thesis, Chongqing University, 2008.

[3]. W.X. Xu, Freeway and Regional Social Economic Development (China Railway Publishing House, Beijing, 2009), pp. 252-256.

[4]. C.W.Sun, "Research on expressway toll pricing-Guangdong as a example," Ph.D. thesis. Jinan University, 2007.

[5]. P.C.Yao and S.J.Wang. Price: Theory \& Practice. Letters 3, 81-85 (2011).

[6]. B.Song and F.Xu. Journal of Management Sciences in China. Letters 14, 86-92 (2011).

[7]. X.Yi. Technology Economics. Letters 34, 108-115 (2015).

[8]. S.Y.Duan and F.Xie. Journal of Industrial Technological Economics. Letters 20, 117-122 (2014).

[9]. W.G.Yu. Contemporary Law Review. Letters 5, 77-82 (2016).

[10]. J.Y.Wang. Value Engineering. Letters 9, 105-108 (2011). 